\title{
Development of the Electromagnetic Regenerative Shock Absorber as an Energy Harvesting Tool for Vehicles
}

\section{Pengembangan Electromagnetic Regeneratif Shock Absorber Sebagai Alat Pemanen Energy Getaran Pada Kendaraan}

\author{
Wanda Afnison ${ }^{1 *}$ Erzeddin Alwi $^{1}$, Hasan Maksum ${ }^{1}$, Bahrul Amin ${ }^{1}$, M.Yasep Setiawan ${ }^{1}$
}

\begin{abstract}
In this study optimization of design oriented to energy generation was carried out while also paying attention to aspects driving comfort that might change due to the installation of a harvesting energy mechanism. One aspect of the change occurred in the type of magnet used, namely a ring type magnet with a type of neodymium material. From the test results obtained by changing the value of the efficiency of the shock absorber after the ERSA mechanism is installed by 2\%, this condition also has an impact on the dissimilarity of the attenuation value obtained by $2 \%$ for the front-rear (left) and (right) wheels. In terms of generation voltage obtained the maximum generation voltage obtained is $25,600 \mathrm{mV}$. Based on the data obtained above it can be concluded an increase in ERSA generation voltage with a ring magnet type with neodymium material and increase in the value of efficiency and shock absorber dissimetry at $2 \%$.
\end{abstract}

\section{Keywords}

Regenerative shock absorber, Neodymium, Dissymetri.

\begin{abstract}
Abstrak
Pada penelitian ini dilakukan optimasi desain yang berorientasi kepada peningkatan energy bangkitan dengan juga memperhatikan aspek kenyamanan berkendara yang mungkin mengalami perubahan akibat pemasangan mekanisme harvesting energy. Salah satu aspek perubahan terjadi pada jenis magnet yang digunakan yaitu magnet dengan tipe ring dengan jenis material neodymium. Dari hasil pengujian diperoleh perubahan nilai efficiency shock absorber setelah dilakukan pemasangan mekanisme ERSA sebesar 2\%, kondisi ini sekaligus berdampak kepada ketidak samaan nilai redaman (dissymetri) redaman yang diperoleh sebesar $2 \%$ untuk roda depan-belakang (kiri) dan (kanan). Dari segi voltase bangkitan diperoleh sebesar $25,600 \mathrm{mV}$. Berdasarkan data yang diperoleh diatas dapat disimpulkan terjadi peningkatan voltase bangkitan ERSA dengan tipe magnet ring dengan material neodymium dan terjadi peningkatan nilai efisiensi dan dissimetri shock absorber sebesar $2 \%$.
\end{abstract}

\section{Kata Kunci}

Regenerative shock absorber, Neodymium, Dissymetri

${ }^{1}$ Jurusan Teknik Otomotif, Universitas Negeri Padang

Jln. Prof. Dr. Hamka Air Tawar Padang 25131 Indonesia

*wandaafnison@ft.unp.ac.id

Submitted : August 03, 2019. Accepted : August 23, 2019. Published : September 01, 2019. 


\section{PENDAHULUAN}

Sektor transportasi dan industri merupakan dua sektor pengguna energi terbesar yang pertumbuhanya terus meningkat dari waktu ke waktu. Bila dilihat menurut sektor pengguna, telah terjadi pergeseran pangsa konsumsi energi final pada beberapa sektor seperti sektor rumah tangga, industri dan transportasi. Berdasarkan data yang dihimpun kementrian ESDM pada Gambar 1 dapat dilihat peningkatan konsumsi energy dari tiap sektor dalam kurung waktu 10 tahun (2000-2010) dimana sektor transportasi naik dari 18\% menjadi 23\% dalam kurung waktu 10 tahun. Hal yang sama juga terjadi di sektor industri dari 32\% menjadi 33\%.

Peningkatan konsumsi energi pada sektor transportasi yang cukup signifikan ini salah satunya disebabkan oleh kegiatan ekonomi yang semakin meningkat khususnya industri manufaktur dan jasa yang berimbas pada mobilitas barang, jasa dan individu.

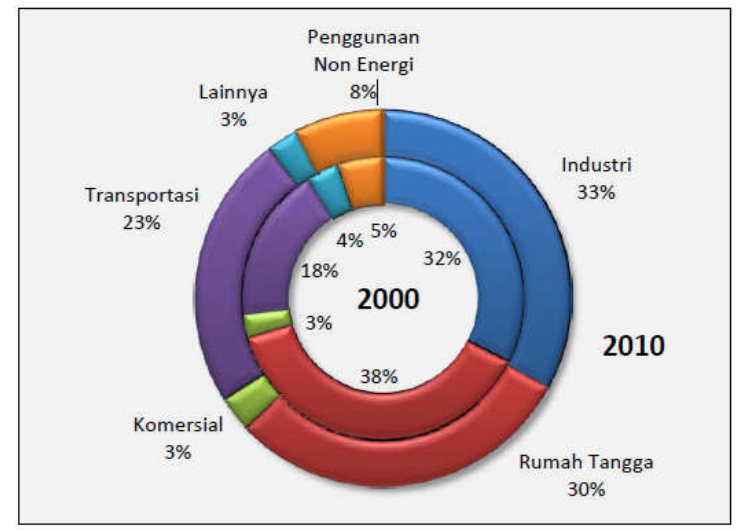

Gambar 1. Sektor pengguna energi di Indonesia[1]

Konsumsi energi pada bidang transportasi yang begitu besar (khususnya transportasi darat) sebenarnya bisa dihemat sedemikina rupa, hal ini dikarenakan hanya $16 \%$ dari energi bahan bakar yang dimanfaatkan untuk mendorong kendaraan. Sisanya sebagian besar energi dari bahan bakar terbuang dalam bentuk panas dan getaran (Center for Energy Transportasion and Environment). Pada gambar 2 dapat dilihat persentase energi yang terbuang pada sebuah kendaraan.

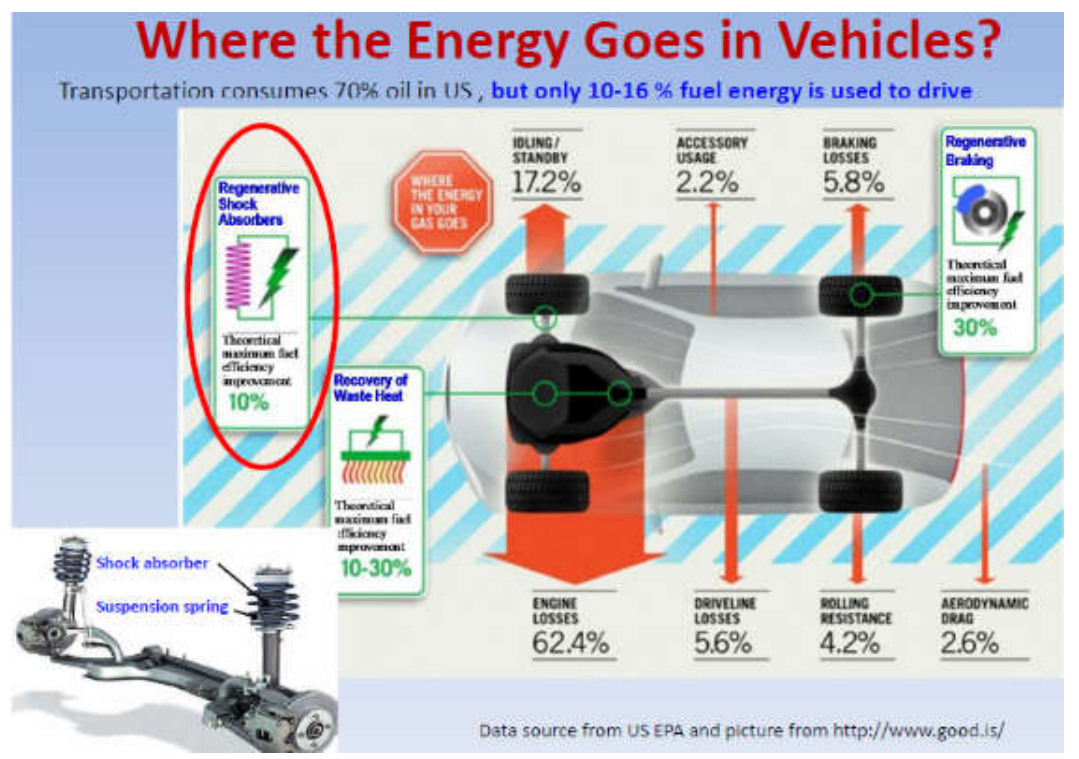

Gambar 2. Distribusi kerugian energi dalam mobil[2] 
Menyadari besarnya energi terbuang yang terjadi pada kendaraan , tentunya dibutuhkan suatu alat yang mampu memanen energi terbuang tersebut sehingga konsumsi bahan bakar pada kendaraan bisa dihemat sedemikian rupa. Salah satu mekanisme alat yang bisa mengurangi loss energi yang terjadi pada kendaraan khususnya pada suspensi adalah mekanisme regenerative shock absorber. Regenerative shock absorber adalah suatu alat (suspensi) yang mampu mengubah getaran yang terjadi pada kendaraaan oleh gangguan kountur permukaan jalan menjadi energi listrik.

Penelitian ini merupakan pengembangan penelitian terdahulu yang didanai PNBP UNP tahun 2017 pada skim PUPT. Dari hasil penelitian terdahulu ditemukan suatu rancangan mekanisme Electromagnetic Regeneratif Shock Absorber (ERSA) yang mampu menghasilkan energy listrik sebesar 1.2 Watt pada kecepatan $20 \mathrm{Km} / \mathrm{H}, 1.6$ Watt pada kecepatan $40 \mathrm{Km} / \mathrm{H}$ dan 0.8 Watt pada kecepatan $60 \mathrm{Km} / \mathrm{H}$. [3]

Pada penelitian ini dilakukan optimasi desain Electromagnetic Regeneratif Shock Absorber (ERSA) sehingga diperoleh titik optimum nilai energy bangkitan yang dihasilkan dan mengacu kepada kenyamanan berkendara.

\section{Regenerative Shock Absorber Massachusets Insititute of Technology}

Pada tahun 2009, tim dari Massachutes Institute of Technology telah menciptakan shock absorber yang mampu menghasilkan energi listrik ditunjukkan pada gambar 3. Prinsip kerja shock absorber ini adalah dengan menggunakan sistem hidrolik, dimana sistem hidrolik ini berfungsi memaksakan cairan untuk masuk menuju turbin dan kemudian turbin akan bergerak memutar generator. Sistem pada shock absorber ini dikontrol oleh sebuah rangkaian elektronik aktif yang berfungsi untuk mengoptimalkan redaman agar lebih nyaman dari peredam konvensional. Berdasarkan hasil dari pengujian regenerative shock absorber ini mampu menghasilkan daya sebesar 200 watt.[4]

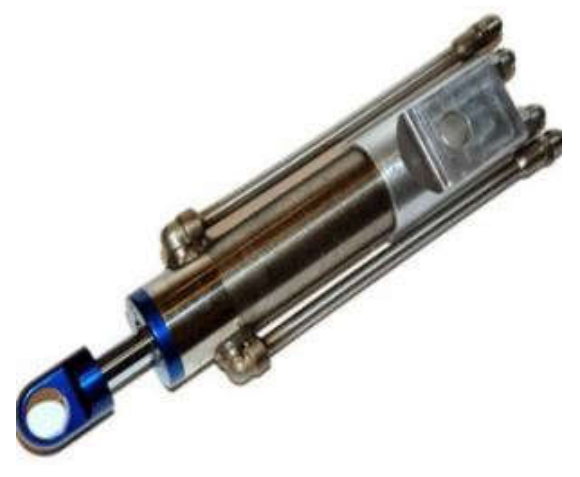

Gambar 3. Regenerative shock absorber Hydraulic oleh Massachutes Institute of Technology[5]

\section{Active electromagnetic suspension system oleh Bart L.J.Gysen dkk}

Pada tahun 2010, tim dari Eindhoven University of Technology membuat sautu alat yaitu active electromagnetic suspension systemyang ditunjukkan pada gambar 4 . Tim ini bekerjasama dengan BMW dan SKF untuk membuat alat tersebut. Perinsip kerja dari alat ini sama halnya dengan prinsip kerja dari linier electromagnetic absorber yang menggunakan magnet dan kumparan yang bergerak translasi sehingga menghasilkan listrik. Suspensi ini termasuk dalam kategori suspense aktif. Berdasarkan hasil pengujian yang telah dilakukan, electromagnetic suspension ini dapat menghasilkan daya lebih kurang sebesar $2 \mathrm{KW}$ dan tingkat kenyamanan dalam berkendara meningkat menjadi $60 \%$. 


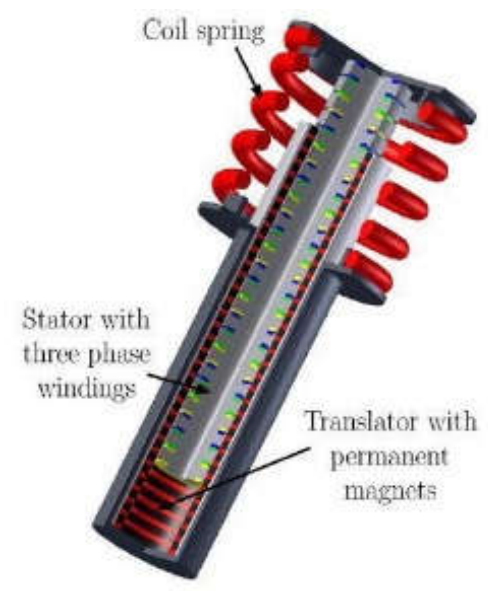

Gambar 4. Active electromagnetic suspension system oleh Bart L.J.Gysen dkk[4]

Hydraulic Electromagnetic Energy-Regenerative Shock Absorber oleh Zhigang Fang dkk

Pada tahun 2013, tim dari Wuhan University of Technology membuat suatu alat yaitu Hydraulic Electromagnetic Shock Absorberyang ditunjukkan pada gambar 5. Prinsip kerja dari alat ini adalah piston dari silinder hidrolik didorong untuk membalas under external stimulus, minyak mengalir ke dalam dan keluar dari penyearah hidrolik dalam langkah kompresi atau stroke ekstensi, dan kemudian minyak mengalir melalui akumulator untukmelemahkan fluktuasi, yang mana digunakan untuk menggerakkan motor hidrolik untuk menghasilkan listrik. Energi listrik dapat mengisi baterai atau pasokan langsung ke kendaraan. Alat ini menggunakan dua akumulator, akumulator 1 digunakan untuk menstabilkan aliran untuk meningkatkan efisiensi kerja dari motor hidrolik, dan fungsi akumulator 2 adalah untuk mencegah distorsi high-frequency dari shock absorber. HESA prototype ini menghasilkan daya sebesar 200 watt di 10 hz-3 mm dan memiliki effisiensi sebesar 16,6 persen.

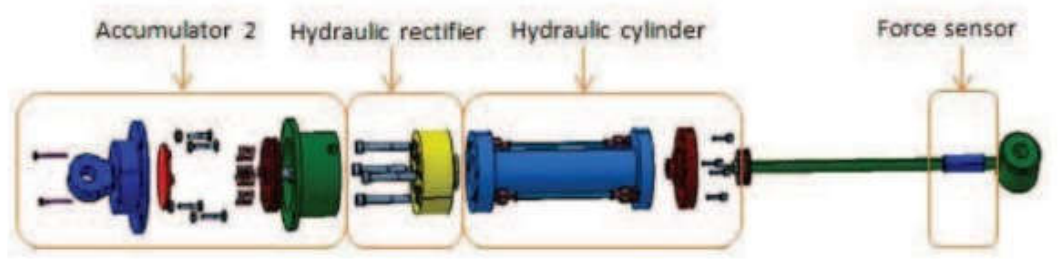

Gambar 5. Hydraulic Electromagnetic Shock Absorber oleh Zhigang Fang dkk[6]

\section{Development and Analysis of a Regenerative Shock Absorber for Vehicle Suspension oleh Harus Laksana Guntur, dkk. Institut Teknologi Sepuluh Nopember (ITS), Surabaya- Indonesia}

Pada tahun 2013, Harus Laksana Guntur, Wiwiek Hendrowati dan Rahman Roy Lubis melakukan pengembangan dan pengujian prototype RSA yang disebut FRSA seperti pada gambar 6. Pengembangan yang dilakukan adalah penyempurnaan Generasi RSA sebelumnyasehingga didapatkan bentuk dan massa dari alat yang lebih baik. Prinsip kerja dari alat ini memanfaatkan gerak naik dan turun pada shock absorber yang di hubungkan pada sistem transmisi gear berupa rack dan piniongear yang berfungsi mengubah gerak translasi (gerak naik turun) menjadi gerak rotasi, lalu gerak rotasi digunakan untuk memutar bevel gear yang telah dipasang one way bearing untuk bisa memanen gerak naik dan turun tersebut, lalu gerakan rotasi tersebut digunakan untuk memutar electromagnetic generator. 
Pengujian yang digunakan adalah dengan memasang suspensi secara bergantian ke suspension test rig, kemudian diuji dengan massa yang sudah di hitung.Hasil yang didapatkan pada pengujian ini adalah pada konvensional shock absorber koefisien redaman didapat sebesar $4338 \mathrm{Ns} / \mathrm{m}$. Sedangkan pada RSA (17 Ohm) sebesar $3190 \mathrm{Ns} / \mathrm{m}$, pada RSA (5.5 Ohm) sebesar $3190 \mathrm{Ns} / \mathrm{m}$, dan pada RSA (0.2 Ohm) sebesar $2552 \mathrm{Ns} / \mathrm{m}$.Untuk transmisibility displacement, titik resonansi konvensional shock absorber dengan $\zeta 0.6$ berada pada 1.3 sedangkan $\zeta 0.8$ berada pada 1.195 untuk RSA 17 Ohm, titik resonansi $\zeta 0.6$ berada pada 0.75 sedangkan $\zeta 0.8$ berada pada 0.67 .

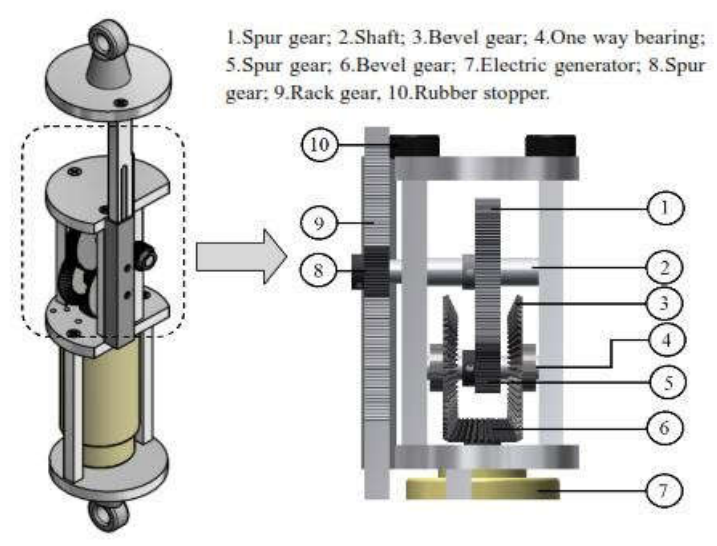

Gambar 6. FRSA dari Intitut Teknologi Sepuluh Nopember, Surabaya[7]

\section{Rancang Bangun Regeneratif Shock Absorber Sebagai Alat Pemanen Energi Getaran Pada Kendaraan dari Fakultas Teknik Universitas Negeri Padang.}

Menggunakan media electromagnetic sebagai mekanisme harvesting energy, tipe Regeneratif Shock Absorber ini mampu menghasilkan energy listrik sebesar 1.2 Watt pada kecepatan $20 \mathrm{Km} / \mathrm{H}, 1.6$ Watt pada kecepatan $40 \mathrm{Km} / \mathrm{H}$ dan 0.8 Watt pada kecepatan 60 $\mathrm{Km} / \mathrm{H}[3]$. Pemilihan mekanisme electromagnetic dikarenakan nilai loss of energinya yang rendah dibanding mekanisme lain.

Penelitian ini dijadikan acuan pengembangan dimana peneliti memprediksi nilai energy listrik bangkitan yang dihasilkan masih bisa untuk ditingkatkan lagi. Berikut bentuk perancangan Electromagnetic Regeneratif Shock Absorber dari fakultas Teknik Universitas Negeri Padang.

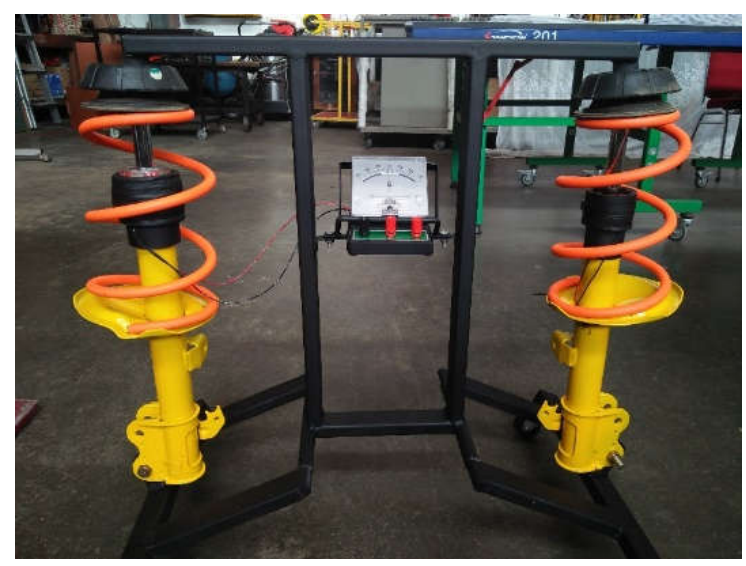

Gambar 7. Electromagnetic Regeneratif Shock Absorber dari Jurusan Teknik Otomotif Universitas Negeri Padang[8] 


\section{METODE PENELITIAN}

Penelitian ini dilakukan dengan metode eksperimen. Dimana Elektomagnetic Regeneneratif Shock Absorber (ERSA) dipasang pada kendaraan dan dilakukan pengujian dengan alat suspension test di laboratorium terpadu Fakultas Teknik UNP. Dari hasil pengujian diperoleh voltase bangkitan dari mekanisme harvesting energy dan respon kendaraan.

\section{Konsep Desain}

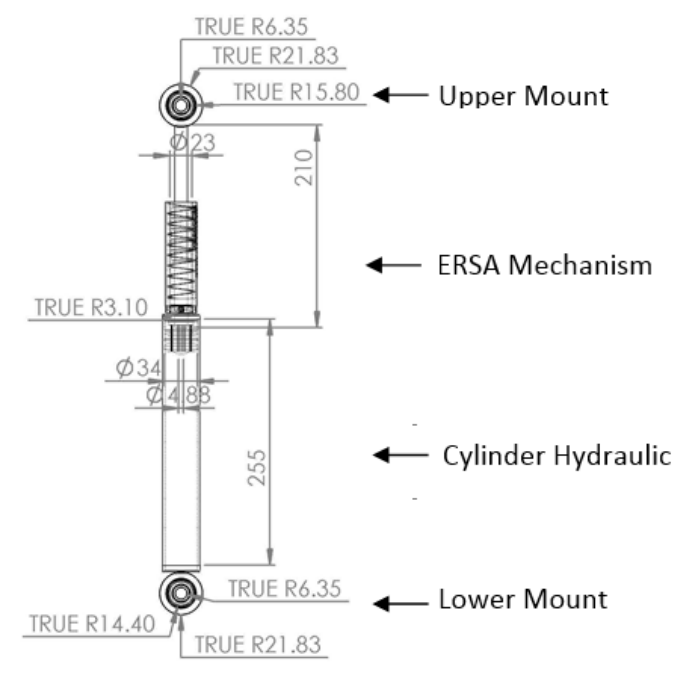

Gambar 8. Konsep desain ERSA

\section{HASIL DAN PEMBAHASAN}

\section{Perancangan Awal}

Berdasarkan hasil evaluasi penelitian sebelumnya dimana ditemui beberapa permasalahan antaranya: minimnya ruang gerak (dispalement) magnet, konstruksi magnet yang terlalu besar dan masih rendahnya tegangan yang dihasilkan. Maka pada penelitian ini dilakukan penyempurnaan baik dari segi desain manufaktur dan material yang digunakan.

Sebelum masuk ke proses manufaktur, terlebih dahulu dilakukan pengujian panjang stroke (displacement) magnet saat proses pengujian. Ini dilakukan agar konstruksi magnet yang dibuat tidak melebihi stroke maksimal shock absorber. Sehingga rancangan magnet yang dibuat tidak rusak dalam melakukan pengujian. Berikut proses pengujian panjang stroke (displacement) shock absorber.

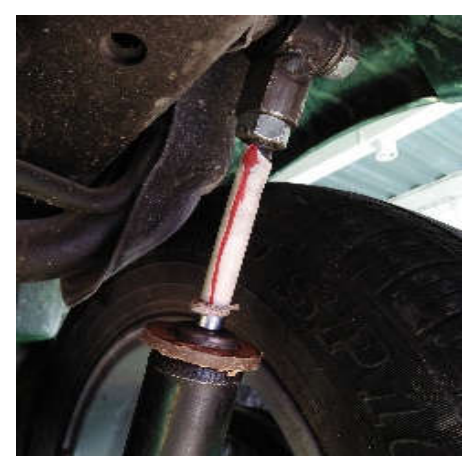

Gambar 9. Pengujian panjang stroke (displacement) shock absorber

Dari hasil pengujian diperoleh panjang stroke maksimal shock absorber adalah sebesar 15 $\mathrm{cm}$. Data ini kemudian dijadikan acuan dalam perancangan dimensi harvesting energy ERSA. 


\section{Proses Manufaktur}

Setelah konsep desain shock absorber diperoleh maka langkah selanjutnya adalah pemilihan material sesuai dengan kebutuhan dan konstruksi shock absorber. Pada mekanisme harvesting energy kali ini menggunakan menggunakan jenis ring magnet dengan bahan neodymium, berbeda dengan penelitian sebelumnya yang menggunakan ferrite magnet.

Perubahan ini dilakukan dengan harapan diperoleh peningkatan voltase bangkitan yang lebih besar dari magnet sebelumnya. Berikut spesifikasi magnet yang digunakan.

Tabel 1: Spesifikasi magnet permanen

\begin{tabular}{|c|c|c|c|c|c|}
\hline Magnet Type & $\begin{array}{l}\text { Remanence } \\
(\mathrm{Br}) \\
\mathrm{mT} \\
(\mathrm{kGs})\end{array}$ & $\begin{array}{l}\text { Coercive Force } \\
(\mathrm{Hc}) \\
\mathrm{kA} / \mathrm{m} \\
(\mathrm{kOe})\end{array}$ & $\begin{array}{l}\text { Intrinsic } \\
\text { Coercive force } \\
(\mathrm{Hci}) \\
\mathrm{kA} / \mathrm{m} \\
(\mathrm{kOe})\end{array}$ & $\begin{array}{l}\text { Max. Energy } \\
\text { product } \\
(\mathrm{BH}) \max \\
\mathrm{kJ} / \mathrm{m} 3 \\
(\mathrm{MGOe})\end{array}$ & $\begin{array}{l}\text { Max. Operating } \\
\text { temperature } \\
\text { TW }\end{array}$ \\
\hline $\begin{array}{l}\text { Neodymium } \\
\text { N52 } \\
\text { Ferrite magnet } \\
\text { Y } 23\end{array}$ & $\begin{array}{l}1430-1480 \\
(14.3-14.8) \\
320-370 \\
(3.2-3.7)\end{array}$ & $\begin{array}{l}\geq 796 \\
(\geq 10.0) \\
170-190 \\
(2.14-2.39)\end{array}$ & $\begin{array}{l}\geq 876 \\
(\geq 11) \\
190-230 \\
(2.39-289)\end{array}$ & $\begin{array}{l}382-406 \\
(48-51) \\
20.0-25.5 \\
(2.5-3.2)\end{array}$ & $80^{\circ}$ \\
\hline
\end{tabular}

Magnet berfungsi sebagai rotor yang bergerak melintasi kumparan kawat. Magnet dipasang pada bagian rod shock absorber sehingga dapat bergerak translasi jika shock absorber terkena gaya eksitasi yang diakibatkan kontur permukaan jalan. Berikut proses pembuatan dudukan magnet permanen:

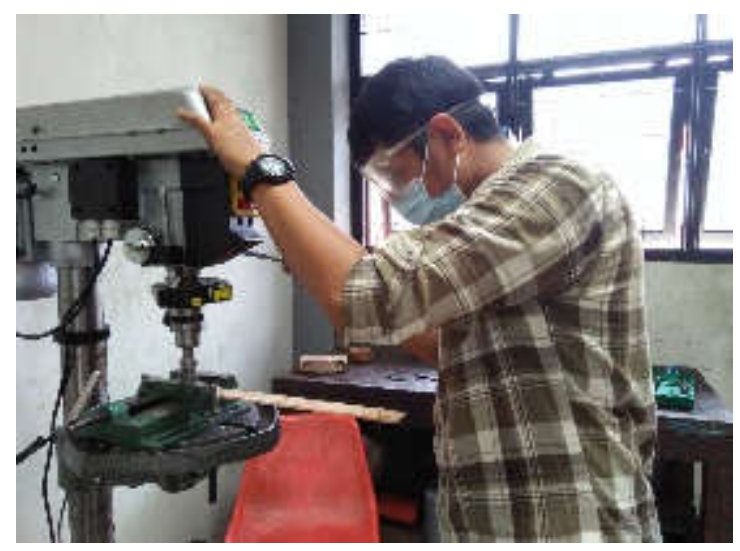

Gambar 10: Prosess manufaktur ERSA

Komponen utama selanjutnya adalah coil yang berfungsi menangkap gerakan naik turun magnet bersama rod shock absorber sehingga terjadi beda potensial diantara kedua ujung kawat. Kawat tembaga yang digunakan untuk membuat lilitan adalah kawat tembaga dengan diameter 0,2 $\mathrm{mm}$ dengan total panjang kawat yang digunakan $5 \mathrm{~m}$.

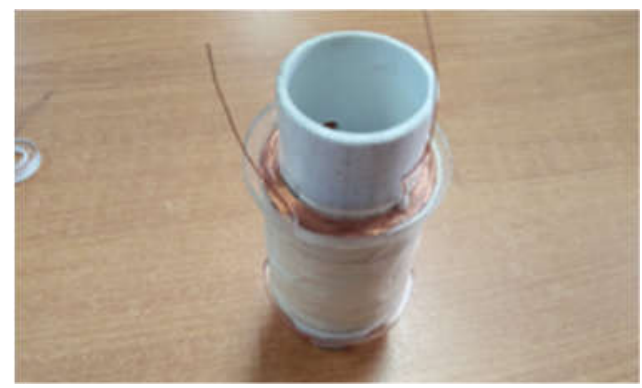

Gambar 11: Lilitan kawat (coil) 
Setelah dua komponen utama mekanisme harvesting energy (magnet permanen dan coil) selesai dibuat maka langkah selajutnya adalah pemasangan mekanisme harvesting energy pada batang (rod) shock absorber. Magnet permanen berada pada posisi rod (bagian bergerak) sedangkat lilitan kawat (coil) berada pada posisi diam yaitu pada silinder hydrolik shock absorber.

Shock absorber lengkap dengan mekanisme harvesting energinya dapat dilihat pada gambar 13. Sampai pada tahap ini regenerative shock absorber sudah siap untuk dilakukan pengambilan data.

(a)

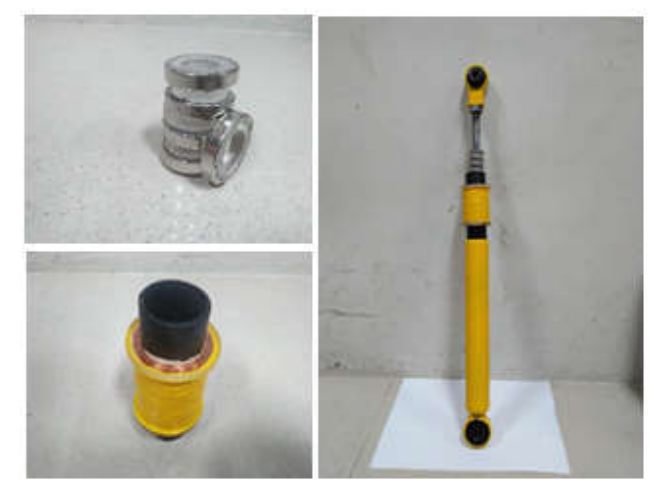

(c)

\section{Proses Pengujian}

Gambar 13. (a) Pemasangan magnet, (b) coil/lilitan, (c) ERSA lengkap.

Tahapan pengujian regenerative shock absorber diawali dengan proses pemasangan shock absorber pada mobil. Proses pemasangan dilakukan di workshop pengujian kendaraan Jurusan Teknik Otomotif di laboratorium terpadu Fakultas Teknik UNP. Pekerjaan ini dibantu oleh 4 orang mahasiswa yang memiliki peran dan fungsi masing-masing. Mulai dari pengoperasian alat suspension test, driver, operator osiloscope dan operator computer.

Pemasangan Shock Absorber

Proses awal dalam melakukan pengujian adalah dengan melakukan penggantian shock absorber standar yang terpasang pada kendaraan dengan shock absorber yang sudah terpasang mekanisme ERSA. Proses pemasangan dilakukan di workshop pengujian kendaraan Jurusan Teknik Otomotif UNP. Gambar 14

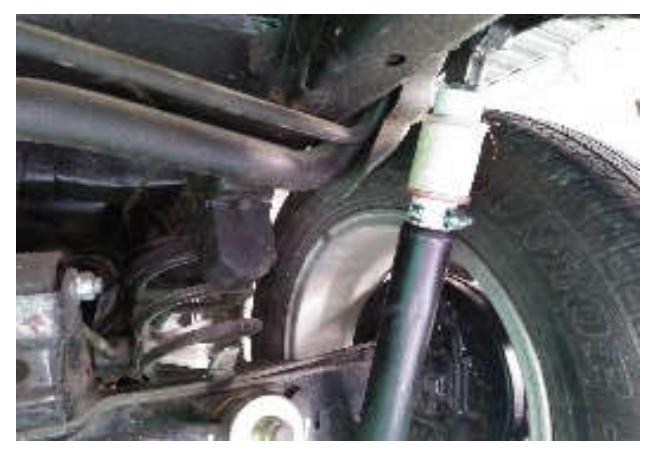

Gambar 14. Proses pemasangan regenerative shock absorber

Pengkondisan peralatan pengujian

Sebelum dilakukan pengujian terlebih dahulu dilakukan kalibrasi alat uji diantaranya suspension test dan ossiloscope. Pengkondisian ini penting untuk menjaga akurasi hasil pengujian. 


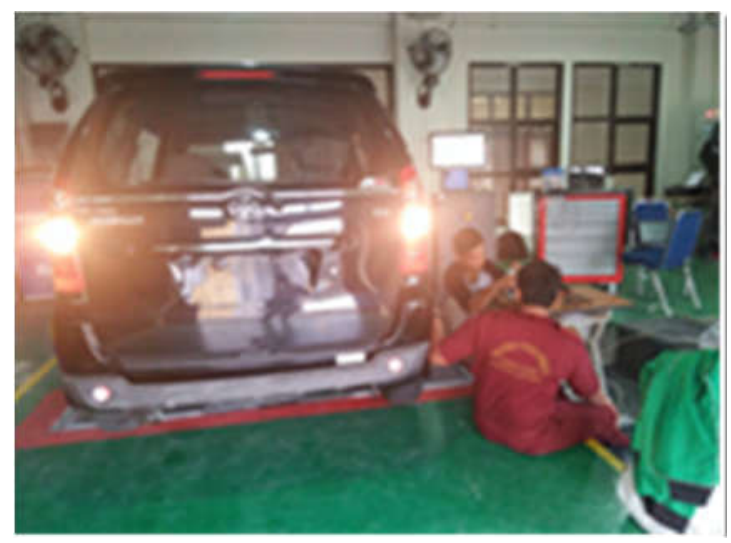

\section{Proses Pengujian}

Gambar 15. Proses pengkondisian peralatan pengujian[1]

Setelah seluruh peralatan dikalibrasi maka langkah selajutnya adalah melakukan proses pengujian. Pada dasarnya proses pengujian dapat dibagi menjadi dua proses: proses pengujian respon kendaraan dan peroses pengukuran voltase bangkitan dari ERSA. Untuk meningkatkan akurasi data, proses pengujian dilakukan sebanyak 3 kali tahapan dan hasil yang diambil adalah rata-rata dari seluruh proses pengujian. Tabel 2 menunjukkan respon kendaraan dan Gambar 20 adalah hasil pengujian voltase bangkitan dari ERSA

\section{Hasil Pengujian}

\section{Tabel 2: Respon kendaraan}

\begin{tabular}{|l|c|}
\hline Designations & Information \\
\hline Left wheel efficiency (\%) E1 & 73 \\
\hline Right wheel efficiency (\%) E1 & 75 \\
\hline Dissymmetry (\%) E1 & 2 \\
\hline Left wheel weighing E1 & 123 \\
\hline Right wheel weighing E1 & 338 \\
\hline Axle weighing E1 & 461 \\
\hline Designations & Information \\
\hline Left wheel efficiency (\%) E2 & 73 \\
\hline Right wheel efficiency (\%) E2 & 75 \\
\hline Disssmmetry (\%) E2 & 2 \\
\hline Left wheel weighing E2 & 121 \\
\hline Right wheel weighing E2 & 335 \\
\hline Axle weighing E2 & 456 \\
\hline Total weighing & 917 \\
\hline
\end{tabular}

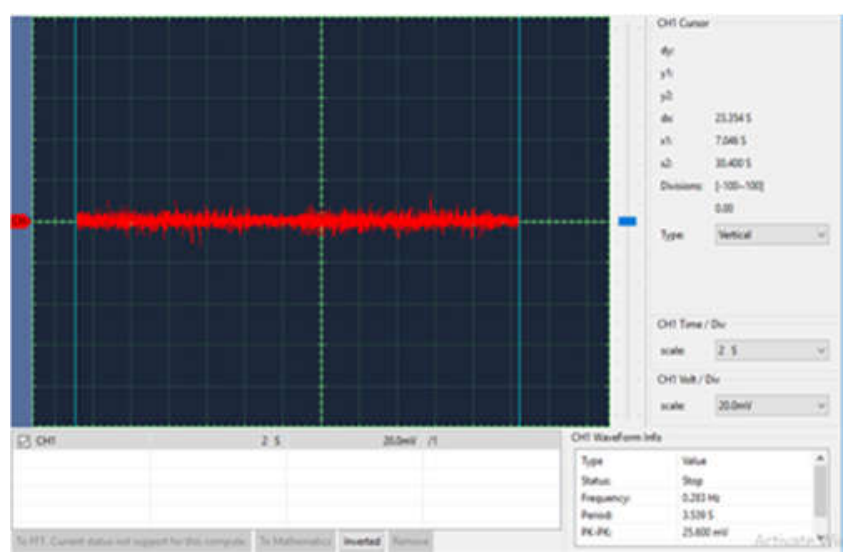

Gambar 20. Hasil pengujian voltase bangkitan ERSA 


\section{Analisa Hasil}

Dari data pengujian respon kendaraan diperoleh nilai efisiensi redaman shock absorber untuk roda kiri 72\% dan roda kanan 75\%. Terdapat perbedaan persentase efisiensi shock absorber sekitar 3\%. Kondisi ini disebabkan oleh pemasangan shock absorber yang menambah nilai redaman shock absorber sehingga meningkatkan efisiensi redaman.

Penambahan mekanisme harvesting energy juga mengakibatkan persentase dissymetri redaman shock absorber berubah. Dari hasil pengujian terdapat 2\% persentase dissymetri antara shock kiri-kanan (depan).

Untuk nilai voltase bangkitan diperoleh data gelombang terbesar (Peak-Peak) sebesar $25,600 \mathrm{mV}$. Nilai ini adalah nilai maksimum voltase bangkitan yang dihasilkan mekanisme ERSA.

\section{SIMPULAN DAN SARAN}

\section{Simpulan}

Dari penelitian yang dilakukan dapat disimpulkan bahwa dengan melakukan optimasi jenis dan material magnet dari bagnet batang menjadi magnet ring dengan material molybdenum mampu meningkatkan voltase listrik bangkitan yang mampu dihasilkan ERSA sebesar 25,6 mV. Dari segi respon kendaraan, pemasangan ERSA tidak terlalu berpengaruh dimana nilai efisiensi dan dissimetry shock absorber sebesar 2\%. Data ini diharapkan menjadi acuan dalam pengembangan ERSA kedepan sehingga diperoleh desain ERSA yang mampu memperoleh hasil energy bangkitan yang lebih baik lagi.

\section{Saran}

Untuk menyempurnakan desain ERSA selanjutnya dapat dilakukan optimasi pada sektor coil dan air gab antara magnet dan lilitan. Keterlibatan tim pengembangan ERSA dari multi disiplin ilmu sangat diperlukan agar proses riset dan pengembangan ERSA dapat berjalan cepat.

\section{DAFTAR RUJUKAN}

[1] C. Lan and W. Qin, "Enhancing ability of harvesting energy from random vibration by decreasing the potential barrier of bistable harvester," Mech. Syst. Signal Process., vol. 85, pp. 71-81, 2017.

[2] T. Ion, A. Emsa, E. Emsa, and I. Icpe-ca, “Analysis of Electromagnetic Regenerative," vol. 77, pp. 2-9, 2015.

[3] W. Afnison and B. Amin, "DISTRIBUSI VISCOUS, FRICTION DAN ELECTRIC DUMPING PADA REGENERATIF SHOCK ABSORBER ( RSA ) TIPE HYDRAULIC ELECTRO MECHANIC SHOCK ABSORBER ( HEMSA )," vol. 17, no. 2, 2017.

[4] J. J. H. Paulides and E. A. Lomonova, "Active Electromagnetic Suspension System for Improved Vehicle Dynamics," no. April, 2010.

[5] B. L. J. Gysen, S. Member, J. L. G. Janssen, and S. Member, "Design Aspects of an Active Electromagnetic Suspension System for Automotive Applications," no. May 2014, 2009.

[6] Z. Jin-Qiu, P. Zhi-Zhao, Z. Lei, and Z. Yu, "A review on energy-regenerative suspension systems for vehicles," Lect. Notes Eng. Comput. Sci., vol. 3 LNECS, pp. 1889-1892, 2013.

[7] W. Afnison and H. L. Guntur, "Studi Karakteristik Regeneratif Shock Absorber Double Silinder Hydraulic Actuator Dengan Variasi Viskositas Oli,” pp. 186-193, 2015.

[8] H. Maksum, W. Purwanto, W. Afnison, U. N. Padang, and C. Author, "DESIGN OF ELECTROMAGNETIC REGENERATIVE SHOCK ABSORBER AS A TOOL OF HARVESTING VIBRATION ENERGY," vol. 15, no. 50, pp. 1-7, 2018. 


\section{Biodata Penulis}

Wanda Afnison, dilahirkan di Sariak Laweh, 9 April 1989. Menyelesaikan S1 pada program studi Pendidikan Teknik Otomotif Jurusan Teknik Otomotif FT - UNP Padang tahun 2011 dan pendidikan Pascasarjana (S2) Magister Teknik di jurusan Teknik Mesin Program Pascasarjana ITS Surabaya dengan bidang konsentrasi Desain Sistem Mekanikal pada tahun 2015. Sejak tahun 2015 sampai sekarang menjadi staf pengajar di jurusan Teknik Otomotif FT - UNP.

Erzeddin Alwi, adalah dosen di Jurusan Teknik Otomotif, Fakultas Teknik Universitas Negeri Padang sejak 1985 hingga sekarang, menyelesaikan Pendidikan S1 dan S2 di Universitas Negeri Padang. Bidang keahlian yang dikuasai diantaranya Teknik Sepeda Motor dan Teknik Kendaraan Ringan. Saat ini aktif sebagai kepala laboratorium di lab Jurusan Teknik Otomotif UNP

Hasan Maksum, adalah dosen di Jurusan Teknik Otomotif, Fakultas Teknik Universitas Negeri Padang sejak 1991 hingga sekarang, menyelesaikan Pendidikan S1 dan S3 di Universitas Negeri Padang. Gelar master diperoleh dari Universitas Gadjah Mada.

Bahrul Amin, adalah dosen di Jurusan Teknik Otomotif, Fakultas Teknik Universitas Negeri Padang sejak 1986 hingga sekarang, menyelesaikan Pendidikan S2 di Universitas Negeri Padang. Bidang keahlian yang dikuasai diantaranya Teknik Sepeda Motor dan Teknik Kendaraan Ringan.

M.Yasep Setiawan, lahir di Salimpauang, 30 September 1989. Sarjana Pendidikan di Jurusan Teknik Otomotif FT - UNP 2011. Tahun 2014 memperoleh gelar Magister Teknik di program studi Rekayasa Konversi Energi jurusan Teknik Mesin Program Pascasarjana ITS Surabaya. Staf pengajar di Jurusan Teknik Otomotif FT - UNP sejak tahun 2015 sampai sekarang. 
